\title{
DOIS CRÍTICOS, PARA QUE SERVEM?
}

\section{Alberto Pucheu}

( COELHO, Eduardo Prado. Mecânica dos Fluidos. Lisboa: Casa da Moeda, 1983: 15.$)$

* (SANTOS, Roberto Corrêa. Para uma teoria da interpretação; semiologia, literatura e interdisciplinaridade. Rio de Janeiro: Forense Universitária, 1989: 26.)
Desde um discurso privilegiador de um suposto saber acumulativo que busca acessar, clarificar e transmitir seu objeto de estudo, a crítica e o ensino literários vivem o desconforto de lidar, de maneira demasiadamente instrumental e subserviente a seu objeto, com uma escrita criadora que não se deixa apropriar por nada de externo a si que a ambicione confiscar. Acreditando muitas vezes apreender o objeto, quando, de fato, preenchem um vão que, inapreensível, insiste em permanecer vazio, a crítica e o ensino literários não obtêm mais do que um entulhamento da obra literária, perdendo, consequentemente, o que dela é fundamental. Suas tentativas são de suprir a falta, suturá-la, apagando até as cicatrizes que deixam os últimos vestígios da costura que, ilusoriamente, cola o vazio. Nestes casos, o dilema que se mostra é o de, através da diferença entre conhecimento demonstrativo e criação, pleitear uma via de acesso para a obra inacessível, apropriar-se da obra inapropriável.

Nas certeiras palavras de Eduardo Prado Coelho em um texto declaradamente inspirado em Estâncias, de Giorgio Agamben, o “"universitário' [forjando simulacros de apropriabilidade] procura cercar a obra literária com todo um ritual sádico em que o saber funciona, na sua acumulação ilimitada, como forma de predação.”* A mesma prevenção contra um predomínio do universitário como predador é defendida por Roberto Corrêa dos Santos, ao afirmar que, exercido no vão, na brecha, na rachadura e na ruptura, o "saber não se faz por acúmulo, nem por sofreguidão". 'A dificuldade da crítica literária também é a de como se tornar capaz da intensidade da obra, já que, por inabilidade ou fragilidade, ela merece, segundo sua autorreflexão reveladora de seu complexo de inferioridade, ser esquecida em nome da privilegiada. ${ }^{1}$ Seja pelo sadismo entulhador, predador, acumulador ou sôfrego, seja pelo complexo de rebocado ou a síndrome cinzenta de quem assume sua linguagem

\footnotetext{
${ }^{1}$ A esse respeito, ver meu próprio ensaio Pelo colorido, para além do cinzento, no livro: Pelo colorido, para além do cinzento; a literatura e seus entornos interventivos. Rio de Janeiro: Azougue Editorial, 2007: 11-26.
} 
como secundária e, portanto, parasitária em relação à obra criadora, os dois dilemas mostram a crise da crítica e do ensino literários.

Por outro lado, a característica principal de uma crítica filosófica e de uma crítica poética da literatura é a consciência de não ser instrumental, demonstrativa ou transmissora de uma obra prévia externa a si. Nelas, nada existe como tentativa de clarificação de qualquer sentido oculto. Não desejando se reduzir a um acesso ou a uma adesão ao texto abordado, mesmo e, sobretudo, quando fala dele, a crítica filosófica e a crítica poética da literatura trabalham justamente pela realização do que mantenha entre si e a obra abordada um espaço de respiração cada vez maior, se empenham na construção de um fosso impeditivo cada vez mais largo entre si e a obra abordada. Uma crítica filosófica e uma crítica poética garantem a inacessibilidade e a inapropriabilidade da obra ao mesmo tempo em que, com isso, se asseguram igualmente enquanto obra, como discurso primeiro, sem que haja qualquer discurso rebocado por outro. Nesta lida, com uma margem de desvinculação requerida, ambos os textos são igualmente instauradores e preservam suas instaurações e autonomias.

Em um texto - não à toa intitulado Carta a um crítico severo - em que cumpre uma crítica a um crítico, abordando a maneira como, em seus livros que tematizam outros filósofos, se relaciona com as obras alheias e com a história da filosofia, Deleuze escreve:

Mas minha principal maneira de me safar nessa época foi concebendo a história da filosofia como uma espécie de enrabada, ou, o que dá no mesmo, de imaculada concepção. Eu me imaginava chegando pelas costas de um autor e lhe fazendo um filho, que seria seu, e no entanto seria monstruoso. Que fosse seu era muito importante, porque o autor precisava efetivamente ter dito tudo aquilo que eu lhe fazia dizer. Mas que o filho fosse monstruoso também representava uma necessidade, porque era preciso passar por toda espécie de descentramentos, deslizes, quebras, emissóes secretas que me deram muito prazer.

Para Gilles Deleuze, que desde o começo desejava ensaiar uma saída da história da filosofia, falar de outra obra é enrabar seu autor, falar mesmo por cima de quem a escreveu, ou seja, falar por sobre ela, rasurando-a, borrando-a, sobrescrevendo-a, tachando-a. Violentando-a. Pondo-se a caminho desde o pensamento do autor de quem se está falando, a partir das palavras que saíram de suas mãos e boca, aparentando estar falando do próprio autor, fazê-lo dizer o que jamais diria, criar, com ele, um filho, mas desde que se-
- (DELEUZE, Gilles. Conversações. Trad. Pál Pelbart. São Paulo: Editora 34, 1992: 14.) 
* (AGAMBEN, Giorgio. Estâncias. Trad. Selvino José Assmann. Belo Horizonte: Editora UFMG, 2007: 32.)

'(DELEUZE, Gilles. Conversações. op. cit.:12.)

(Ibidem: 17.) ja monstruoso, desde que, resguardando uma semelhança qualquer com o texto que o incitou, seja, a um só tempo, integralmente diferente de sua proveniência. Curiosamente, a autoconsciência desse monstro gerado por descentramentos, deslizes e quebras permite, com sua existência monstruosa, a manutenção da obra da qual ele nasceu em condição de diferença. Para o monstro crítico da filosofia (cuja comunicação com seu objeto se dá sob a forma da privação e da carência), ${ }^{*}$ importa muito a manutenção explícita do fosso entre as duas obras, a preservação do furo, do aberto, do inapropriável de qualquer obra. Na passagem citada, o pensador francês mantém o furo, o aberto e o inapropriável pela declaração de que, ao falar de outros autores, sua realização é monstruosa. O monstro garante o acréscimo, o a mais, a anomalia, a diferença tanto do texto crítico quanto da obra abordada, mas jamais a substituição desta por aquele nem o apagamento daquele por esta.

É isto - o monstro, o anômalo - que o crítico literário habitual, o comentador e o professor não conseguem criar, buscando exatamente um filho que, legítimo, seja o mais semelhante possível do texto do qual fala, registrado em cartório por ele, hierarquizado por ele, normatizado por ele. O texto crítico (filosófico ou poético) é, entretanto, aquele que propaga uma reunião de transformações no texto abordado, cuja distância, podendo ser maior ou menor, sempre existe. Deleuze pode escrever ao crítico que publicou um livro sobre ele: "Ainda uma vez, é problema seu, e desde o começo eu avisei que este livro não me concernia, que eu não o leria ou só o leria mais tarde, e como um texto referente exclusivamente a você". Antes de concernir ao autor abordado, o texto de um crítico concerne ao próprio crítico; antes de mostrar o poder ou a impotência que tem sobre o autor abordado, o texto de um crítico mostra seu próprio poder ou impotência sobre si mesmo; antes de falar dos princípios do autor abordado, o texto crítico fala de seus próprios princípios. Antes de o texto crítico ser um fora almejando alcançar finalmente o dentro da obra trabalhada, o que se dá é uma relação entre dois foras. Fora com fora, relacionando-se por esbarros que empurram o outro para lugares a que ele não iria sozinho.

O grau das lentes dos óculos críticos é elevado o suficiente ou baixo o bastante para forçar uma deformação obrigatória no que está sendo visto. Nenhuma transparência, nenhum acesso a um outro se faz possível. Não há nada a explicar, nada a compreender, nada a interpretar. É do tipo de ligação elétrica. ${ }^{*}$ Em nome da dife- 
rença monstruosa, a escrita deleuziana se afastará cada vez mais da semelhança, da necessidade de que o filho, ainda que monstruoso, seja também do outro. Cada vez mais uma escrita dos afetos, das intensidades, das experimentações será trazida à tona. Como a inapropriabilidade e a inacessibilidade típicas da crítica filosófica e poética, o filósofo francês dirá: "Falamos do fundo daquilo que não sabemos, do fundo de nosso próprio subdesenvolvimento".* Do mesmo modo que, em outro lugar, eu já havia feito o elogio da lembrança de uma passagem de Diógenes de Laêrtios, volto aqui a afirmar que nunca é demasiado relembrar a anedota contada por ele, mencionando que Sócrates, o indivíduo histórico, ouvindo Platão ler o Lísis, teria exclamado: Por Heraclés! Quantas mentiras esse rapaz me faz dizer!" Mentir... Mascarar... Trair... Criar um monstro... Enrabar Sócrates... É o que faz o jogo dos diálogos platônicos ao lidar com o outro, com o outro amado.

Apesar de raramente privilegiados pela crítica literária preponderante, os exemplos de uma crítica enrabadora e monstruosa, que se quer criadora e inventiva ou preservadora da inacessibilidade e inapropriabilidade, não são poucos nem periféricos. Tanto como poeta quanto como crítico, Baudelaire foi um dos principais marcos inauguradores da Modernidade, mas se, enquanto poeta, jamais abriu mão de uma poesia crítica, enquanto crítico, jamais abriu mão da superioridade de uma crítica poética sobre as demais:

Eu creio sinceramente que a melhor crítica é a que é divertida e poética; não aquela, fria e algébrica, que, com o pretexto de tudo explicar, não sente nem ódio nem amor, e se despoja voluntariamente de qualquer espécie de temperamento; mas sim - como um belo quadro é a natureza refletida por um artista - a que será este quadro refletido por um espírito inteligente e sensível. Dessa forma, a melhor análise de um quadro poderá ser um soneto ou uma elegia.*

Assumir que a melhor crítica é divertida e poética significa dizer que, nos melhores casos, uma análise de determinada obra de arte pode ser uma nova obra que traga em si a diferença de uma assinatura, o sui generis da criação de quem a realizou. Nada aqui se compara ao mencionado ritual sádico do saber que, predador da obra, se impóe pelo desejo sôfrego de acumulação ilimitada ou de explicação totalizante. Nada aqui se realiza por uma busca de transparência que teria acesso ao sentido da obra abordada, conseguindo, assim, apropriar-se dela. Nada aqui tenta o engano de uma reprodução fidedigna que abandone a felicidade de sonhar.
" (Ibidem: 15.)

- (LAÊRTIOS, Diôgenes. Vidas e doutrinas dos filósofos ilustres. Trad. Mário da Gama Kury. Brasília: UnB, 1988: 93.)

- (BAUDELAIRE, Charles. "Salão de 1846". In: Poesia e Prosa. Edição organizada por Ivo Barroso. Rio de Janeiro: Editora Nova Aguilar, 1995: 673.) 
- (AGAMBEN, Giorgio. L'homme sans contenu. Trad. Carole Walter. Paris: Circé, 1996: 24.)
Nada aqui se faz em nome de um menosprezo da crítica enquanto um discurso segundo em relação ao suposto primeiro da obra de arte. Do mesmo modo que o poeta se apropria do movimento crítico, divertida e poética, esta crítica se apropria, antes, do movimento criador da obra de arte, daquilo que um dia Agamben chamou de "um operari particular e irredutível, o operar artístico", fazendo com que o escritor de As Flores do Mal possa afirmar que "o leitor não se surpreenderá, portanto, que eu considere o poeta o melhor de todos os críticos. ${ }^{2}$

${ }^{2}$ BAUDELAIRE, Charles. Richard Wagner e Tannhäuser em Paris. In: Poesia e Prosa: 924. No que diz respeito a esse trânsito entre o crítico e o poético, vale lembrar tanto a presença dos dois quartetos do soneto Correspondências no texto a que essa nota se refere quanto o ensaio Salão de 1846, onde está transcrita a seguinte passagem de Hoffmann, de grande proximidade com o poema citado: "Não é apenas quando sonho, mas também quando estou acordado, que descubro uma analogia e uma íntima comunhão entre as cores, os sons e os perfumes." Colaborando com esse entrelaçamento entre o crítico e o poético em Baudelaire, Agamben afirma que "todo soneto sobre as Correspondências pode ser lido como uma transcrição das impressões de estranhamento produzidas por uma visita à Exposição Universal. No citado artigo, Baudelaire, a propósito das impressões do visitante frente à mercadoria exótica, evoca "estes cheiros que já não são os do toucador, estas flores misteriosas cuja cor profunda entra no olho despoticamente, enquanto sua forma irrita o olhar, estes frutos cujo gosto engana e desloca os sentidos, e revela ao palácio das ideias que pertencem ao olfato, todo este mundo de harmonias novas entrará lentamente nele, penetrá-lo-á pacientemente... toda esta vitalidade desconhecida será acrescentada à sua própria vitalidade; algumas milhares de ideias e de sensações enriquecerão seu dicionário de mortal”. Além disso, fala com o desprezo do pedante que, frente a tal espetáculo, é incapaz de "correr agilmente sobre o imenso teclado das correspondências" (Estâncias. op. cit.: 77.). Dentro da visada baudelairiana aqui explicitada, o poema Os Faróis pode ser lido como um exemplo de uma análise da pintura plenamente realizada em um poema: Rubens, rio do olvido, jardim da preguiça, / Divã de carne tenra onde amar é proibido,/ Mas onde a vida aflui e eternamente viça,/ Como o ar no céu e o mar dentro do mar contido;// Da Vinci, espelho tão sombrio quão profundo, / Onde anjos cândidos, sorrindo com carinho/Submersos em mistério, irradiam-se ao fundo/ Dos gelos e pinhais que lhes selam o ninho;/ Rembrandt, triste hospital repleto de lamentos, / Por um só crucifixo imenso decorado, / Onde a oração é um pranto em meio aos excrementos, / E por um sol de inverno súbito cruzado;// Miguel Ângelo, espaço ambíguo em que vagueiam/ Cristos e Hércules, e onde se erguem dos ossários/ Fantasmas colossais que à tíbia luz se arqueiam/E cujos dedos hirtos rasgam seus sudários;/ Impudências de fauno, iras de boxeador,/ Tu que de graças aureolaste os desgraçados, / Coração orgulhoso, homem fraco e sem cor, / Puget, imperador soturno dos forçados;// Watteau, um carnaval de coraçôes ilustres, / Quais borboletas a pulsar por entre os lírios, / Cenários leves inflamados pelos lustres/ Que à insânia incitam este baile de delírios;// Goya, lúgubre sonho de obscuras vertigens, / De fetos cuja carne cresta nos sabás, / De velhas ao espelho e seminuas virgens, / Que a meia ajustam e seduzem Satanás;// Delacroix, lago onde anjos maus banham-se em sangue,/ Na orla de um bosque cujas cores não se apagam/ E onde estranhas fanfarras, sob um céu exangue, / Como um sopro de Weber 
Em Baudelaire, que, dizendo ser o poeta o melhor dos críticos, afirma ter "imenso prazer em assumir o tom lírico para falar dos artistas", " isto se deve ao fato de as obras artísticas criticadas "se oferecerem, não com um caráter literal e preciso, mas com um caráter poético, vão e confuso, e amiúde é o tradutor que inventa as intenções". Para o crítico poético francês, traduzir, interpretar ou criticar é um ato de invenção de modos de dizer e de pensar que, afastando-se do literal, ou seja, da unidade entre o significado e sua expressão significante, acolhe, no desacordo entre a forma e o significado, o vão do negativo a fender e desdobrar o signo supostamente fechado na uniformidade do literal em uma dualidade original do manifestante e da coisa manifestada, do impreciso a mostrar e ocultar simultaneamente todo o dizer e tudo o que aparece. Assim, ao tradutor, ao crítico, cabe entender a linguagem neste caráter poético, vão e confuso, em que nada está predeterminado, em que a linguagem é puro diferimento tanto em relação ao sujeito e ao objeto quanto em relação a si mesma, não propiciando um sentido literal ao que está sendo dito. Cabe ao intérprete, ao crítico, uma criação que sabe não se apropriar da obra de que está falando, mas, ao contrário, resguardá-la em uma zona inacessível através da inventividade crítica. Não à toa, Agamben afirma:

O fundamento desta ambiguidade do significar reside naquela fratura original da presença, que é inseparável da experiência ocidental do ser, e pela qual tudo aquilo que vem à presença como lugar de um diferimento e de uma exclusão, no sentido de que o seu manifestar é, ao mesmo tempo, um esconder-se, o seu estar presente, um faltar. É este co-pertencimento originário da presença e da ausência do aparecer e do esconder que os gregos expressavam na intuição da verdade como alétheia, desvelamento, e é sobre a experiência desta fratura que se baseia o discurso que nós ainda chamamos com o nome grego de "amor à sabedoria". Só porque a presença está dividida e descolada, é possível algo como um "significar"; e só porque não há na origem plenitude, mas diferimento (seja isso interpretado como oposição do ser e do aparecer, seja como harmonia dos opostos ou diferença ontológica do ser e do ente), há necessidade de filosofar.

entre os ramos vagam;// Essas blasfêmias e lamentos indistintos, / Esses Te Deum, essas desgraças, esses ais/ São como um eco a percorrer mil labirintos, / E um ópio sacrossanto aos coraçôes mortais!// É um grito expresso por milhōes de sentinelas,/ Uma ordem dada por milhóes de porta-vozes;/ É um farol a clarear milhóes de cidadelas, / Um caçador a uivar entre animais ferozes!// Sem duivida, Senhor, jamais o homem vos deral Testemunho melhor de sua dignidadel Do que esse atroz soluço que erra de era em eral E vem morrer aos pés de vossa eternidade!.
- (BAUDELAIRE, Charles. "Salão de 1859". In: Poesia e Prosa. op. cit.: 796.)

'(BAUDELAIRE, Charles. "A Arte Filosófica". In: Poesia e Prosa: 791.)

- (AGAMBEN, Giorgio. Estâncias. op. cit.: 219.) 
"BAUDELAIRE, Charles. "Salão de $1859 "$ ". op. cit.: 803.) "(Ibidem.: 803.)

"(lbidem.: 806.)

(BAUDELAIRE, Charles. "A obra e a vida de Eugène Delacroix". In: Poesia e Prosa. op. cit.: 889.)

•(Ibidem.: 889.)

" (BAUDELAIRE, Charles. "Salão de 1846". op. cit.: 673.)

- (BAUdelaire, Charles. "Exposição Universal (1855)". In: Poesia e Prosa. op. cit.: 774 .)

(Ibidem: 889.)
Consequentemente, também a crítica acata a lacuna do poético não-literal (poderia dizer, a lacuna da linguagem em seu diferimento original e no diferimento original da presença), fazendo com que seu texto seja igualmente escrito por um homem imaginativo, cuja faculdade - a imaginação -, para Baudelaire, é a misteriosa "rainha das faculdades" que subordina todas as demais a si. Preferindo "os monstros de [sua] fantasia à trivialidade concreta", a faculdade superior da criação, que sempre gera novos mundos e possibilidades, "contém o espírito crítico", que se sabe livre para novos devaneios instauradores.

Com o encontro do crítico e do criador na imaginação elogiadora dos artifícios, os efeitos da potência do falso na mentira ou na ficção, que se afastam da tentativa de representação fiel da natureza, podem estar muito mais próximos do que Baudelaire às vezes chama de verdade do que a recusa cerrada em mentir que, em nome da pretensão em dizer o suposto verdadeiro, acaba por se afastar integralmente da verdade da arte e da crítica. Para o poeta e crítico francês, os artistas se dividem em realistas ou positivistas (que dizem querer "representar as coisas tais como são, ou tais como seriam, supondo que eu não existisse. $\mathrm{O}$ universo sem o homem.") ${ }^{*}$ e imaginativos (que dizem querer "iluminar as coisas com meu espírito e projetar seu reflexo sobre os outros espíritos"). *No que concerne os críticos, há, portanto, igualmente, um privilégio da imaginação. Se, ainda que possível e mesmo preferido, não é obrigatório que um texto crítico seja um poema ou uma obra de arte, é necessário que, ele mesmo, pela imaginação criadora, invente uma nova possibilidade de pensamento que, diante de um texto poético, vão e confuso, no lugar de encerrar o exclusivo do beco sem saída, abra o maior número de horizontes. ${ }^{*}$ Afastando-se do literal, o texto crítico acata a abertura poética. Assim, portanto, Baudelaire diz ser uma excelente lição de crítica* uma anedota contada acerca de Balzac:

Conta-se que Balzac (quem não escutaria com respeito todas as histórias, por menores que fossem, relativas a esse grande gênio?), estando certa vez diante de um belo quadro, um quadro de inverno, bastante melancólico e imerso num nevoeiro, salpicado de cabanas e de camponeses miseráveis, após ter contemplado uma casinha de onde se elevava uma tênue fumaça, exclamou: "Que lindo! Mas o que estão fazendo nessa cabana? Em que estão pensando? Quais são suas aflições? As colheitas foram boas? Por acaso eles têm contas a pagar?* 
Posicionando-se como suplementar de um texto ausente, a crítica literária busca saber de algo que, complexo, não tem como conhecer, senão pela preservação do complexo; a crítica literária busca saber de algo que, enigmático, não tem como conhecer, senão pela preservação do enigma; a crítica literária busca saber de algo que, ambíguo, não tem como conhecer, senão pela preservação da ambiguidade; a crítica literária busca saber de algo que, paradoxal, não tem como conhecer, senão pela preservação do paradoxo; a crítica literária busca saber de algo que, inapropriável, não tem como conhecer, senão pela preservação da inapropriabilidade; a crítica literária busca saber de algo que, instaurador, não tem como conhecer, senão pela preservação da instauração; a crítica literária busca saber de algo que, literário, não tem como conhecer, senão pela preservação do literário.

\section{Alberto Pucheu}

É poeta e professor de Teoria Literária da UFRJ. Jovem Cientista do Nosso Estado, pela FAPERJ, entre 2007-2009, pertence ao Programa de Pós-Graduação em Letras (Ciência da Literatura), da UFRJ. Publicou os seguintes livros de ensaios: Antonio Cicero por Alberto Pucheu (Rio de Janeiro: EdUERJ, 2010, Coleção Ciranda); O amante da literatura (Rio de Janeiro: Oficina Raquel, 2010); Giorgio Agamben: poesia, filosofia, critica (Rio de Janeiro: Azougue Editorial/FAPERJ, 2010); Pelo colorido, para além do cinzento; a literatura e seus entornos interventivos (Rio de Janeiro: Azougue Editorial/FAPERJ, 2007).

\section{Resumo}

Muitas vezes, a crítica e o ensino literários vivem o desconforto de lidar, de maneira instrumental e subserviente a seu objeto, com uma escrita criadora que não se deixa apropriar por nada de externo a si. Acreditando apreender o objeto, quando, de fato, preenchem um vão que, inapreensível, insiste em permanecer vazio, a crítica e o ensino literários acabam, frequentemente, por perder o que da literatura é fundamental. Por outro lado, a característica principal de uma crítica filosófica e de uma crítica poética da literatura é a consciência de não ser instrumental, demonstrativa ou transmissora de uma obra prévia externa a si. Entre outros, Baudelaire e Deleuze são grandes exemplos destas últimas. 
Key words: instrumental criticism; philosophical criticism; poetical criticism; Baudelaire; Gilles Deleuze.

Mots-clés: critique instrumental; critique philosophique; critique poétique; Baudelaire; Gilles Deleuze.

\section{Abstract}

Very often, critics and literary education face the discomfort of having to deal instrumentally and subserviently with a creative genre of writing which does not allow external appropriation. Believing to apprehend it, while they actually fill a inapprehensible gap that insists in remaining empty, criticism and literary education frequently end up losing what is fundamental to their object, literature. On the other hand, the main feature of philosophical and poetic criticism is the conscience of not being instrumental, demonstrative or the mere carrier of a previous and external work of art. Among others, Baudelaire and Deleuze are good examples of the latters.

\section{Résumé}

Souvent la critique et l'enseignement littéraires éprouvent de la gêne à aborder, de manière instrumentale et trop soumise à son objet, une écriture créatrice qui ne se laisse approprier par rien d'extérieur à soi. Croyant appréhender l'objet, quand en fait ils remplissent un vide insaisissable qui insiste à rester vide, la critique et l'enseignement littéraires finissent fréquemment par perdre ce qui est fondamental dans la littérature. Par contre, la principale caractéristique d'une critique philosophique et d'une critique poétique de la littérature est la conscience de ne pas être instrumentale, démonstrative ou de transmettre une œuvre préalable, externe à soi. Baudelaire et Deleuze, entre autres, sont des grands exemples de ce genre de critique. 